\title{
RAS/RAF/MEK/ERK and PI3K/PTEN/AKT Signaling in Malignant Melanoma Progression and Therapy
}

\author{
Ichiro Yajima, Mayuko Y. Kumasaka, Nguyen Dinh Thang, Yuji Goto, \\ Kozue Takeda, Osamu Yamanoshita, Machiko Iida, Nobutaka Ohgami, \\ Haruka Tamura, Yoshiyuki Kawamoto, and Masashi Kato
}

Unit of Environmental Health Sciences, Department of Biomedical Sciences, College of Life and Health Sciences, Chubu University, Kasugai, Aichi 487-8501, Japan

Correspondence should be addressed to Masashi Kato, katomasa@isc.chubu.ac.jp

Received 12 May 2011; Accepted 9 August 2011

Academic Editor: Pascale Quatresooz

Copyright ( $) 2012$ Ichiro Yajima et al. This is an open access article distributed under the Creative Commons Attribution License, which permits unrestricted use, distribution, and reproduction in any medium, provided the original work is properly cited.

\begin{abstract}
Cutaneous malignant melanoma is one of the most serious skin cancers and is highly invasive and markedly resistant to conventional therapy. Melanomagenesis is initially triggered by environmental agents including ultraviolet (UV), which induces genetic/epigenetic alterations in the chromosomes of melanocytes. In human melanomas, the RAS/RAF/MEK/ERK (MAPK) and the PI3K/PTEN/AKT (AKT) signaling pathways are two major signaling pathways and are constitutively activated through genetic alterations. Mutations of RAF, RAS, and PTEN contribute to antiapoptosis, abnormal proliferation, angiogenesis, and invasion for melanoma development and progression. To find better approaches to therapies for patients, understanding these MAPK and AKT signaling mechanisms of melanoma development and progression is important. Here, we review MAPK and AKT signaling networks associated with melanoma development and progression.
\end{abstract}

Cell signaling pathways are important for understanding not only cancer progression but also all life phenomena, including regulation of cell growth and death, migration, and angiogenesis [1-4]. Moreover, the events are accurately controlled by various intracellular signal transduction molecules $[2,5-7]$. In cancer progression, the signaling is hyperactivated and/or silenced irreversibly. These irreversible losses of control in signal transduction allow cancers to acquire cancer-progression-specific phenotypes, such as antiapoptosis, abnormal proliferation, angiogenesis, and invasion. Previous studies revealed that collapse of signaling control was induced by both genetic and environmental factors [812].

Melanin-producing cells, acquired in several species from fungi to primates in the long evolutionary process, have many advantageous functions for survival strategy [13-19]. Melanocytes, melanin-producing cells that are the origin of melanoma, are developed from neural crest cells with several types of cell signaling pathways and gene expression
[15, 20-22]. Human melanomas are categorized as nevusassociated melanomas and de novo melanomas based on their developmental process. Nevus-associated melanomas are transformants of preexisting benign lesions, and their malignant conversion progresses in a multistep manner [23-26]. De novo melanomas develop without pre-existing benign lesions [6, 27-29]. In humans, most melanomas are thought to have developed de novo. RFP-RET transgenic mice of line 304/B6 (RET mice) are powerful tools for analyses of melanoma with pre-existing benign lesions [6, $30,31]$. The entire process of melanoma development via tumor-free, benign, premalignant, and malignant stages in RET mice corresponds to the multistep melanomagenesis in humans [32]. Recently, we identified ZFP 28, CD109, and c-RET as melanoma-related molecules through analysis of tumors in RET mice $[4,33,34]$.

Melanoma progression is closely associated with oncogenic change: (1) genetic alteration (heritable changes in the DNA sequence such as gene mutations, deletions, amplifications, or translocations) and (2) epigenetic alteration 


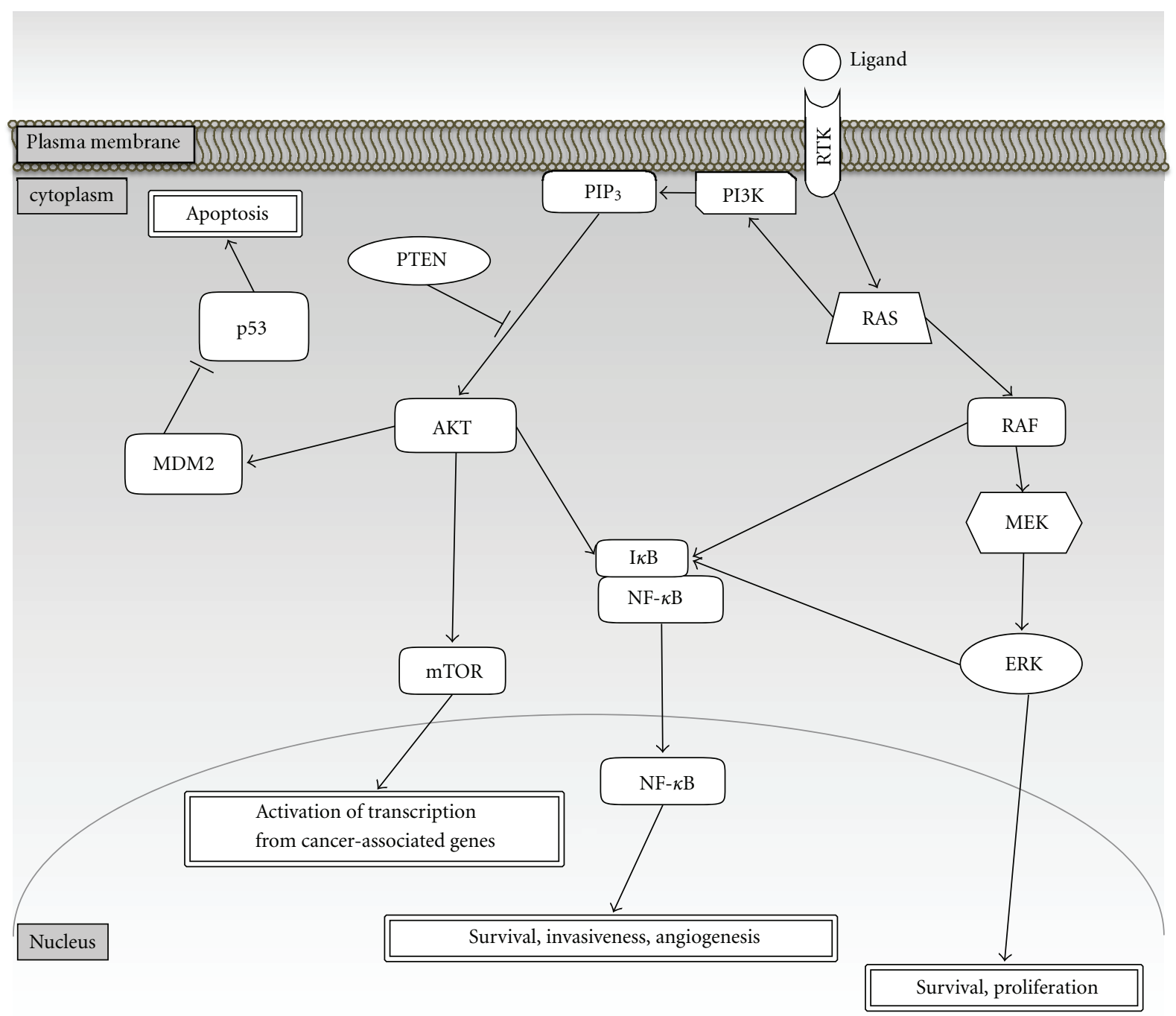

FIgURE 1: Signal transduction in melanoma development and progression. Extracellular signaling (ligand) triggers intracellular signaling through receptors such as tyrosine kinases (RTK). Triggered signals are transduced via verious factors, including tyrosine kinases, phosphatases, inhibitors, cofactors, and transcription factors and affect melanoma development and progression. Abbreviations: AKT thymoma viral proto-oncogene; MDM2 transformed mouse 3T3 cell double minute 2; mTOR mechanistic target of rapamycin; PI3K Phosphoinositide 3-kinase, $\mathrm{PIP}_{3}$, Phosphatidylinositol $(3,4,5)$-trisphosphate; PTEN phosphatase and tensin homolog.

(modulated transcriptional activities by DNA methylations and/or by chromatin alterations). Much information associated with melanoma development such as information on gene mutations, alterations of gene expression patterns, and protein activities has been reported.

The RAS/RAF/MEK/ERK pathway, one of the most well-known pathways involved in melanoma progression, is regulated by receptor tyrosine kinases, cytokines, and heterotrimeric G-protein-coupled receptors [35]. The small G protein RAS (HRAS, KRAS, and NRAS in humans) is localized to the plasma membrane and activates a downstream factor, RAF (ARAF, BRAF and CRAF in humans) followed by sequential activation of MEK and ERK, and this signal is finally transduced to regulation of transcription in the nucleus (Figure 1) [36]. This pathway is constitutively activated by growth factors such as stem cell factor (SCF), fibroblast growth factor (FGF), hepatocyte growth factor (HGF), and glial-cell-derived neurotrophic factor (GDNF) $[37,38]$, though activation of this signal is weak in melanocytes.

ERK is hyperactivated in $90 \%$ of human melanomas [39] by growth factors [40] and by genetic alterations of upstream factors, RAS, and RAF proteins [41]. In humans, NRAS and BRAF genes are mutated in $15 \%$ to $30 \%$ and in $50 \%$ to $70 \%$ of human melanomas, respectively, leading to their permanent activation [41] followed by promotion of proliferation, survival, invasion, and angiogenesis of melanoma [42, 43]. BRAF signaling is also associated with $\mathrm{NF} \kappa \mathrm{B}$ promoter activity. Inhibition of BRAF signaling decreased $\mathrm{NF} \kappa \mathrm{B}$ promoter activity associated with survival, invasiveness and angiogenesis for melanoma formation [44, 45]. 
PTEN, containing a phosphatase domain, is inactivated in $12 \%$ of melanomas through mutation or methylation [46]. A substrate of PTEN, phosphatidylinositol $(3,4,5)$ trisphosphate $\left(\mathrm{PIP}_{3}\right)$ and phosphorylates AKT [47], which activates cell survival, proliferation, cancer promotion, and antiapoptotic signaling through mTOR (mammalian target of rapamycin) and NF- $\kappa$ B pathways in melanoma (Figure 1) [48-51]. RAS can also bind and activate PI3K, resulting in increased AKT activity [52]. MDM2 is a ubiquitin ligase that targets p53 (an apoptosis-associated tumor-suppressor protein) for degradation and is highly expressed in $6 \%$ of dysplastic nevi, $27 \%$ of melanoma in situ, and $56 \%$ of invasive primary and metastatic melanomas [53]. MDM2 is also a substrate for AKT [54-56]. Taken these results indicate that AKT/MDM2 pathway is involved in melanoma progression (Figure 1).

Recently, many persistent studies developed therapeutics and drugs for melanomas. Phase 2 study for melanoma patients was tested by using the combination of bevacizumab, an inhibitor of angiogenesis, and everolimus, an inhibitor of mTOR which is a downstream target of PI3K/PTEN/AKT signaling. In this study, $12 \%$ of malignant melanoma patients achieved major responses [57]. Plexxikon (PLX4032) is a novel selective inhibitor for $\mathrm{BRAF}^{\mathrm{V} 600 \mathrm{E}}$, a major activated mutation observed in $60 \%$ of human melanomas [41]. This inhibitor is dramatically effective in $74-80 \%$ of patients with $\mathrm{BRAF}^{\mathrm{V} 600 \mathrm{E}}$-positive melanomas [58-60]. However, tumors grow and progress again in almost all patients from about 7 months after initial treatment of PLX4032 [58, 60]. Recent studies have revealed that treatment with PLX4032 activates a novel pathway leading to regrowth and reprogression of tumors with bypass of BRAF signaling, resulting in tumors acquiring resistance to the BRAF inhibitor [61-65]. Molecular-based targeted treatments are usually effective only in a subset of patients, and predictive molecular tests are required to identify tumors with an activated targeted pathway and to select patients with a good chance of response. On the other hand, treatment with bortezomib, a $\mathrm{NF}-\kappa \mathrm{B}$ inhibitor, alone or combined with paclitaxel and carboplatin showed no clinical effect on malignant melanoma patients in phase 2 study even though NF- $\kappa \mathrm{B}$ is a downstream target of RAF and AKT [66, 67]. These limited effects indicate that signaling pathways in malignant melanomas may compensate each other to make resistance to molecular-targeted therapy. Thus, molecular mechanisms of melanoma development and progression are complicated and melanoma therapy is still incomplete. Further studies and a better understanding of melanoma development and progression are needed to establish effective therapeutics with few harmful side effects.

\section{Acknowledgments}

This publication was supported by Grants-in-Aid for Scientific Research (B) (no. 20406003), Grant-in-Aid for Exploratory Research (no. 23650241), COE Project (Health Science Hills) for Private Universities (no. S0801055) from the Ministry of Education, Culture, Sports, Science and
Technology (MEXT), Grant-in-Aid for Young Scientists (B) (no. 22791041, 22791092 and 18790738), AA Science Platform Program from the Japan Society for the Promotion of Science (JSPS), Mitsui \& Co. Ltd., Environment Fund (R08C097), Research Grant from the Tokyo Biochemical Research Foundation (TBRF), Research Foundation from the Institute of Science, and Technology Research in Chubu University, the Naito Foundation Natural Science Scholarship, and Chubu University Grants A, B, and CG.

\section{References}

[1] I. Helfrich, I. Scheffrahn, S. Bartling et al., "Resistance to antiangiogenic therapy is directed by vascular phenotype, vessel stabilization, and maturation in malignant melanoma," Journal of Experimental Medicine, vol. 207, no. 3, pp. 491-503, 2010.

[2] M. Kato, T. Hattori, H. Ito et al., "Serum-soluble Fas levels as a marker to distinguish allergic and nonallergic rhinitis," Journal of Allergy and Clinical Immunology, vol. 103, no. 6, pp. 12131214, 1999.

[3] W. Liu, M. Kato, A. A. Akhand et al., "4-hydroxynonenal induces a cellular redox status-related activation of the caspase cascade for apoptotic cell death," Journal of Cell Science, vol. 113, part 4, pp. 635-641, 2000.

[4] Y. Ohshima, I. Yajima, K. Takeda et al., "c-RET molecule in malignant melanoma from oncogenic RET-carrying transgenic mice and human cell lines," PLoS ONE, vol. 5, no. 4, Article ID e10279, 2010.

[5] M. Kato, K. Takeda, Y. Kawamoto et al., "Repair by Src kinase of function-impaired RET with multiple endocrine neoplasia type $2 \mathrm{~A}$ mutation with substitutions of tyrosines in the $\mathrm{COOH}$-terminal kinase domain for phenylalanine," Cancer Research, vol. 62, no. 8, pp. 2414-2422, 2002.

[6] M. Kato, K. Takeda, Y. Kawamoto et al., "RET tyrosine kinase enhances hair growth in association with promotion of melanogenesis," Oncogene, vol. 20, no. 51, pp. 7536-7541, 2001.

[7] M. Kato and W. Wickner, "Vam10p defines a Sec18p-independent step of priming that allows yeast vacuole tethering," Proceedings of the National Academy of Sciences of the United States of America, vol. 100, no. 11, pp. 6398-6403, 2003.

[8] K. Hossain, A. A. Akhand, M. Kato et al., "Arsenite induces apoptosis of murine $\mathrm{T}$ lymphocytes through membrane raft-linked signaling for activation of c-Jun amino-terminal kinase," Journal of Immunology, vol. 165, no. 8, pp. 4290-4297, 2000.

[9] M. Kato, T. Iwashita, A. A. Akhand et al., "Molecular mechanism of activation and superactivation of Ret tyrosine kinases by ultraviolet light irradiation," Antioxidants and Redox Signaling, vol. 2, no. 4, pp. 841-849, 2000.

[10] M. Kato, T. Iwashita, K. Takeda et al., "Ultraviolet light induces redox reaction-mediated dimerization and superactivation of oncogenic Ret tyrosine kinases," Molecular Biology of the Cell, vol. 11, no. 1, pp. 93-101, 2000.

[11] N. Ohgami, M. Ida-Eto, T. Shimotake et al., "C-Ret-mediated hearing loss in mice with Hirschsprung disease," Proceedings of the National Academy of Sciences of the United States of America, vol. 107, no. 29, pp. 13051-13056, 2010.

[12] N. Ohgami, T. Kondo, and M. Kato, "Effects of light smoking on extra-high-frequency auditory thresholds in young adults," 
Toxicology and Industrial Health, vol. 27, no. 2, pp. 143-147, 2011.

[13] M. S. Blois, "Vitamin D, sunlight, and natural selection," Science, vol. 159, no. 815, p. 652, 1968.

[14] S. Kamei, I. Yajima, H. Yamamoto et al., "Characterization of a novel member of the FGFR family, HrFGFR, in Halocynthia roretzi," Biochemical and Biophysical Research Communications, vol. 275, no. 2, pp. 503-508, 2000.

[15] M. Kumasaka, S. Sato, I. Yajima, C. R. Goding, and H. Yamamoto, "Regulation of melanoblast and retinal pigment epithelium development by Xenopus laevis Mitf," Developmental Dynamics, vol. 234, no. 3, pp. 523-534, 2005.

[16] M. Kumasaka, S. Sato, I. Yajima, and H. Yamamoto, "Isolation and developmental expression of tyrosinase family genes in Xenopus laevis," Pigment Cell Research, vol. 16, no. 5, pp. 455462, 2003.

[17] S. Sato, R. Toyoda, Y. Katsuyama et al., "Structure and developmental expression of the ascidian TRP gene: insights into the evolution of pigment cell-specific gene expression," Developmental Dynamics, vol. 215, no. 3, pp. 225-237, 1999.

[18] I. Yajima, K. Endo, S. Sato et al., "Cloning and functional analysis of ascidian Mitf in vivo: insights into the origin of vertebrate pigment cells," Mechanisms of Development, vol. 120, no. 12, pp. 1489-1504, 2003.

[19] I. Yajima and L. Larue, "The location of heart melanocytes is specified and the level of pigmentation in the heart may correlate with coat color," Pigment Cell and Melanoma Research, vol. 21, no. 4, pp. 471-476, 2008.

[20] I. Puig, I. Yajima, J. Bonaventure, V. Delmas, and L. Larue, "The tyrosinase promoter is active in a subset of vagal neural crest cells during early development in mice," Pigment Cell and Melanoma Research, vol. 22, no. 3, pp. 331-334, 2009.

[21] N. Tsukiji, D. Nishihara, I. Yajima, K. Takeda, S. Shibahara, and H. Yamamoto, "Mitf functions as an in ovo regulator for cell differentiation and proliferation during development of the chick RPE," Developmental Biology, vol. 326, no. 2, pp. 335-346, 2009.

[22] I. Yajima, S. Sato, T. Kimura et al., "An L1 element intronic insertion in the black-eyed white (Mitf(mi-bw)) gene: the loss of a single Mitf isoform responsible for the pigmentary defect and inner ear deafness," Human Molecular Genetics, vol. 8, no. 8, pp. 1431-1441, 1999.

[23] J. M. Chiang, Y. H. W. Chou, S. C. Ma, and J. R. Chen, "Influence of age on adenomatous polyposis coli and p53 mutation frequency in sporadic colorectal cancer-Rarity of co-occurrence of mutations in APC, K-ras, and p53 genes," Virchows Archiv, vol. 445, no. 5, pp. 465-471, 2004.

[24] S. M. Hede, I. Hansson, G. B. Afink et al., "GFAP promoter driven transgenic expression of PDGFB in the mouse brain leads to glioblastoma in a Trp53 null background," GLIA, vol. 57, no. 11, pp. 1143-1153, 2009.

[25] S. Olschwang, R. Hamelin, P. Laurent-Puig et al., "Alternative genetic pathways in colorectal carcinogenesis," Proceedings of the National Academy of Sciences of the United States of America, vol. 94, no. 22, pp. 12122-12127, 1997.

[26] H. Zhu, J. Acquaviva, P. Ramachandran et al., "Oncogenic EGFR signaling cooperates with loss of tumor suppressor gene functions in gliomagenesis," Proceedings of the National Academy of Sciences of the United States of America, vol. 106, no. 8, pp. 2712-2716, 2009.

[27] R. J. Friedman, D. S. Rigel, A. W. Kopf et al., "Favorable prognosis for malignant melanomas associated with acquired melanocytic nevi," Archives of Dermatology, vol. 119, no. 6, pp. 455-462, 1983.

[28] S. Kaddu, J. Smolle, P. Zenahlik, R. Hofmann-Wellenhof, and H. Kerl, "Melanoma with benign melanocytic naevus components: reappraisal of clinicopathological features and prognosis," Melanoma Research, vol. 12, no. 3, pp. 271-278, 2002.

[29] S. C. Weatherhead, M. Haniffa, and C. M. Lawrence, "Melanomas arising from naevi and de novo melanomas-does origin matter?" British Journal of Dermatology, vol. 156, no. 1, pp. 72-76, 2007.

[30] M. Kato, M. Takahashi, A. A. Akhand et al., "Transgenic mouse model for skin malignant melanoma," Oncogene, vol. 17, no. 14, pp. 1885-1888, 1998.

[31] M. Kato, K. Takeda, Y. Kawamoto et al., "c-Kit-targeting immunotherapy for hereditary melanoma in a mouse model," Cancer Research, vol. 64, no. 3, pp. 801-806, 2004.

[32] M. Y. Kumasaka, I. Yajima, K. Hossain et al., "A novel mouse model for de novo melanoma," Cancer Research, vol. 70, no. 1, pp. 24-29, 2010.

[33] Y. Ohshima, I. Yajima, M. Y. Kumasaka et al., "CD109 expression levels in malignant melanoma," Journal of Dermatological Science, vol. 57, no. 2, pp. 140-142, 2010.

[34] I. Yajima, M. Kumasaka, N. D. Thang et al., "Zinc finger protein 28 as a novel melanoma-related molecule," Journal of Dermatological Science, vol. 55, no. 1, pp. 68-70, 2009.

[35] J. Goodall, C. Wellbrock, T. J. Dexter, K. Roberts, R. Marais, and C. R. Goding, "The Brn-2 transcription factor links activated BRAF to melanoma proliferation," Molecular and Cellular Biology, vol. 24, no. 7, pp. 2923-2931, 2004.

[36] V. Gray-Schopfer, C. Wellbrock, and R. Marais, "Melanoma biology and new targeted therapy," Nature, vol. 445, no. 7130, pp. 851-857, 2007.

[37] M. Bohm, G. Moellmann, E. Cheng et al., "Identification of p90(RSK) as the probable CREB-Ser133 kinase in human melanocytes," Cell Growth and Differentiation, vol. 6, no. 3, pp. 291-302, 1995.

[38] N. Narita, A. Tanemura, R. Murali et al., "Functional RET G691S polymorphism in cutaneous malignant melanoma," Oncogene, vol. 28, no. 34, pp. 3058-3068, 2009.

[39] C. Cohen, A. Zavala-Pompa, J. H. Sequeira et al., "Mitogenactived protein kinase activation is an early event in melanoma progression," Clinical Cancer Research, vol. 8, no. 12, pp. 37283733, 2002.

[40] K. Satyamoorthy, G. Li, M. R. Gerrero et al., "Constitutive mitogen-activated protein kinase activation in melanoma is mediated by both BRAF mutations and autocrine growth factor stimulation," Cancer Research, vol. 63, no. 4, pp. 756759, 2003.

[41] H. Davies, G. R. Bignell, C. Cox et al., "Mutations of the BRAF gene in human cancer," Nature, vol. 417, no. 6892, pp. 949954, 2002.

[42] V. C. Gray-Schopfer, S. da Rocha Dias, and R. Marais, "The role of B-RAF in melanoma," Cancer and Metastasis Reviews, vol. 24, no. 1, pp. 165-183, 2005.

[43] A. Sharma, N. R. Trivedi, M. A. Zimmerman, D. A. Tuveson, C. D. Smith, and G. P. Robertson, "Mutant V599EB-Raf regulates growth and vascular development of malignant melanoma tumors," Cancer Research, vol. 65, no. 6, pp. 2412-2421, 2005.

[44] P. Dhawan and A. Richmond, "A novel NF- $\kappa$ B-inducing kinase-MAPK signaling pathway up-regulates NF- $\kappa$ B activity in melanoma cells," Journal of Biological Chemistry, vol. 277, no. 10, pp. 7920-7928, 2002. 
[45] J. Liu, K. G. Suresh Kumar, D. Yu et al., "Oncogenic BRAF regulates $\beta$-Trcp expression and NF- $\kappa \mathrm{B}$ activity in human melanoma cells," Oncogene, vol. 26, no. 13, pp. 1954-1958, 2007.

[46] D. C. Bennett, "How to make a melanoma: what do we know of the primary clonal events?" Pigment Cell and Melanoma Research, vol. 21, no. 1, pp. 27-38, 2008.

[47] T. Maehama and J. E. Dixon, "PTEN: a tumour suppressor that functions as a phospholipid phosphatase," Trends in Cell Biology, vol. 9, no. 4, pp. 125-128, 1999.

[48] P. Dhawan, A. B. Singh, D. L. Ellis, and A. Richmond, "Constitutive activation of Akt/protein kinase B in melanoma leads to up-regulation of nuclear factor- $\kappa \mathrm{B}$ and tumor progression," Cancer Research, vol. 62, no. 24, pp. 7335-7342, 2002.

[49] D. Kim, S. Kim, H. Koh et al., "Akt/PKB promotes cancer cell invasion via increased motility and metalloproteinase production," FASEB Journal, vol. 15, no. 11, pp. 1953-1962, 2001.

[50] F. Meier, B. Schittek, S. Busch et al., "The Ras/Raf/MEK/ERK and PI3K/AKT signaling pathways present molecular targets for the effective treatment of advanced melanoma," Frontiers in Bioscience, vol. 10, no. 3, pp. 2986-3001, 2005.

[51] B. K. Park, X. Zeng, and R. I. Glazer, "Akt1 induces extracellular matrix invasion and matrix metalloproteinase-2 activity in mouse mammary epithelial cells," Cancer Research, vol. 61, no. 20, pp. 7647-7653, 2001.

[52] A. Sekulic, P. Haluska Jr., A. J. Miller et al., "Malignant melanoma in the 21st century: the emerging molecular landscape," Mayo Clinic Proceedings, vol. 83, no. 7, pp. 825-846, 2008.

[53] D. Polsky, K. Melzer, C. Hazen et al., "HDM2 protein overexpression and prognosis in primary malignant melanoma," Journal of the National Cancer Institute, vol. 94, no. 23, pp. 1803-1806, 2002.

[54] L. D. Mayo and D. B. Donner, "A phosphatidylinositol 3kinase/Akt pathway promotes translocation of Mdm2 from the cytoplasm to the nucleus," Proceedings of the National Academy of Sciences of the United States of America, vol. 98, no. 20, pp. 11598-11603, 2001.

[55] Y. Ogawara, S. Kishishita, T. Obata et al., "Akt enhances Mdm2-mediated ubiquitination and degradation of p53," Journal of Biological Chemistry, vol. 277, no. 24, pp. 2184321850, 2002.

[56] B. P. Zhou, Y. Liao, W. Xia, Y. Zou, B. Spohn, and M. C. Hung, "HER-2/neu induces p53 ubiquitination via Akt-mediated MDM2 phosphorylation," Nature Cell Biology, vol. 3, no. 11, pp. 973-982, 2001.

[57] J. D. Hainsworth, J. R. Infante, D. R. Spigel et al., "Bevacizumab and everolimus in the treatment of patients with metastatic melanoma: a phase 2 trial of the Sarah Cannon Oncology Research Consortium," Cancer, vol. 116, no. 17, pp. 4122-4129, 2010.

[58] G. Bollag, P. Hirth, J. Tsai et al., "Clinical efficacy of a RAF inhibitor needs broad target blockade in BRAF-mutant melanoma," Nature, vol. 467, no. 7315, pp. 596-599, 2010.

[59] P. B. Chapman, A. Hauschild, C. Robert et al., "Improved survival with vemurafenib in melanoma with BRAF V600E mutation," New England Journal of Medicine, vol. 364, no. 26, pp. 2507-2516, 2011.

[60] K. T. Flaherty, I. Puzanov, K. B. Kim et al., "Inhibition of mutated, activated BRAF in metastatic melanoma," New England Journal of Medicine, vol. 363, no. 9, pp. 809-819, 2010.
[61] H. T. Arkenau, R. Kefford, and G. V. Long, "Targeting BRAF for patients with melanoma," British Journal of Cancer, vol. 104, no. 3, pp. 392-398, 2011.

[62] C. M. Johannessen, J. S. Boehm, S. Y. Kim et al., "COT drives resistance to RAF inhibition through MAP kinase pathway reactivation," Nature, vol. 468, no. 7326, pp. 968-972, 2010.

[63] R. Nazarian, H. Shi, Q. Wang et al., "Melanomas acquire resistance to B-RAF(V600E) inhibition by RTK or N-RAS upregulation," Nature, vol. 468, no. 7326, pp. 973-977, 2010.

[64] P. I. Poulikakos and N. Rosen, "Mutant BRAF melanomasdependence and resistance," Cancer Cell, vol. 19, no. 1, pp. 11$15,2010$.

[65] J. Villanueva, A. Vultur, J. T. Lee et al., "Acquired resistance to BRAF inhibitors mediated by a RAF kinase switch in melanoma can be overcome by cotargeting MEK and IGF1R/PI3K," Cancer Cell, vol. 18, no. 6, pp. 683-695, 2010.

[66] G. A. Croghan, V. J. Suman, W. J. Maples et al., "A study of paclitaxel, carboplatin, and bortezomib in the treatment of metastatic malignant melanoma: a phase 2 consortium study," Cancer, vol. 116, no. 14, pp. 3463-3468, 2010.

[67] S. N. Markovic, S. M. Geyer, F. Dawkins et al., "A phase II study of bortezomib in the treatment of metastatic malignant melanoma," Cancer, vol. 103, no. 12, pp. 2584-2589, 2005. 


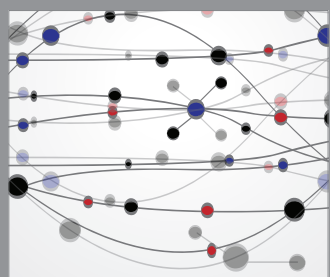

The Scientific World Journal
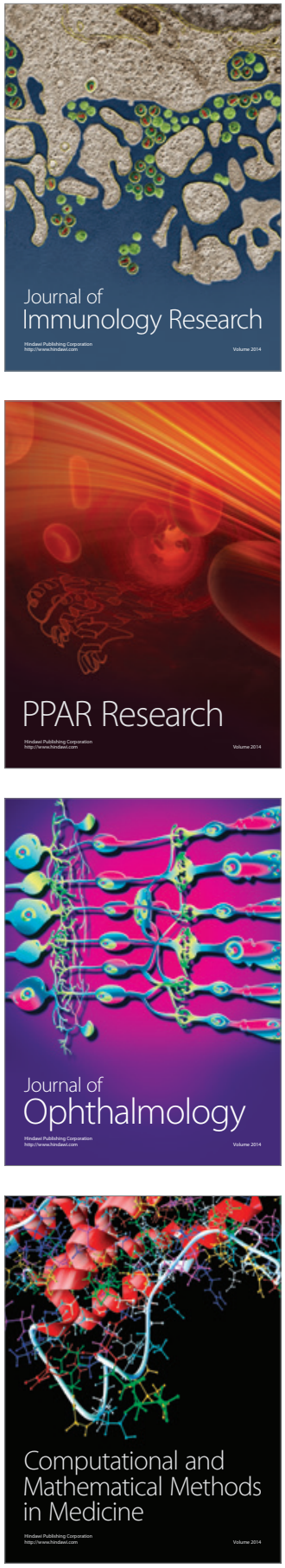

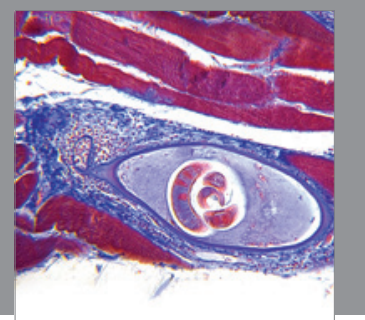

Gastroenterology

Research and Practice
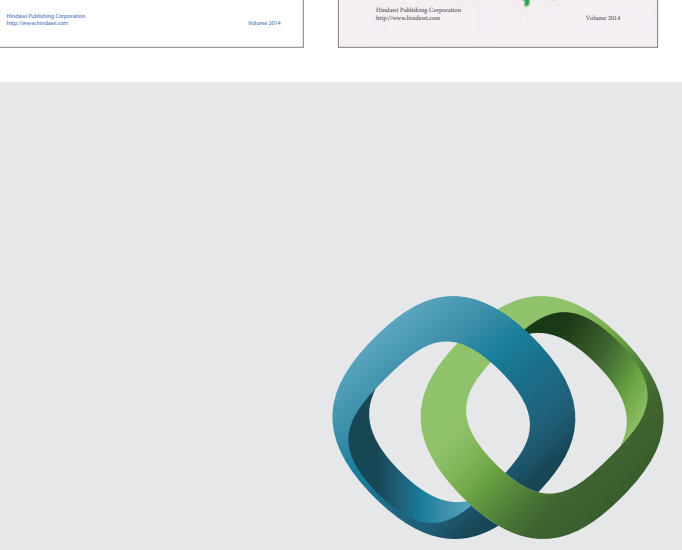

\section{Hindawi}

Submit your manuscripts at

http://www.hindawi.com
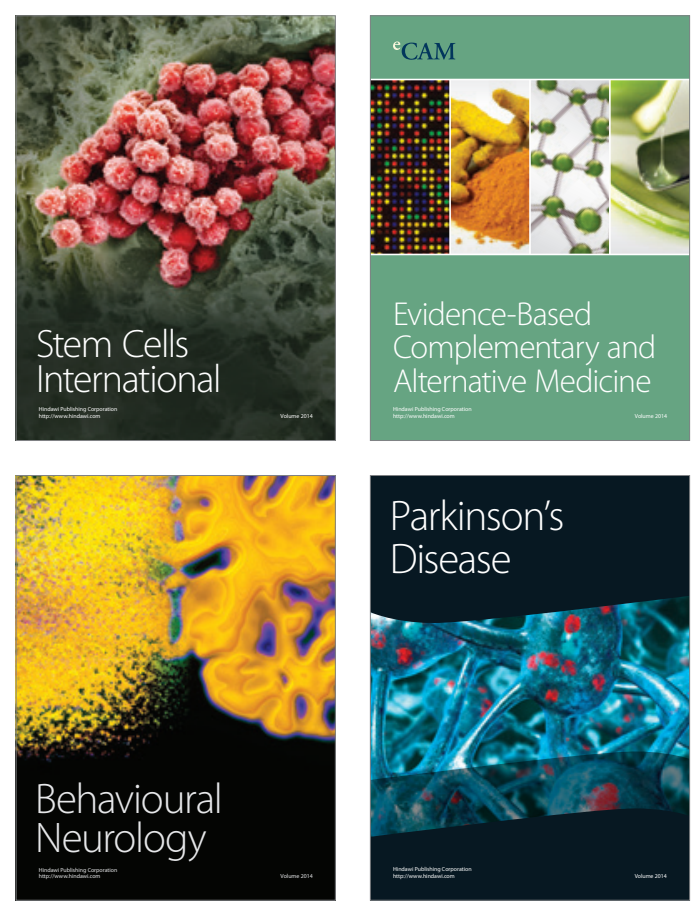

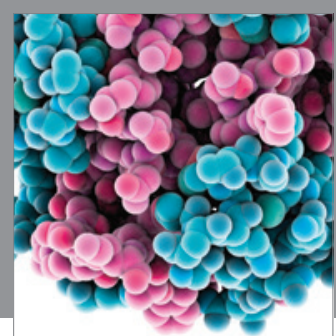

Journal of
Diabetes Research

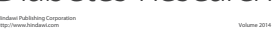

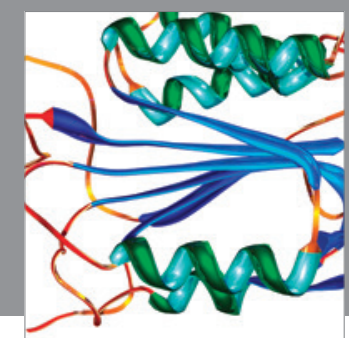

Disease Markers
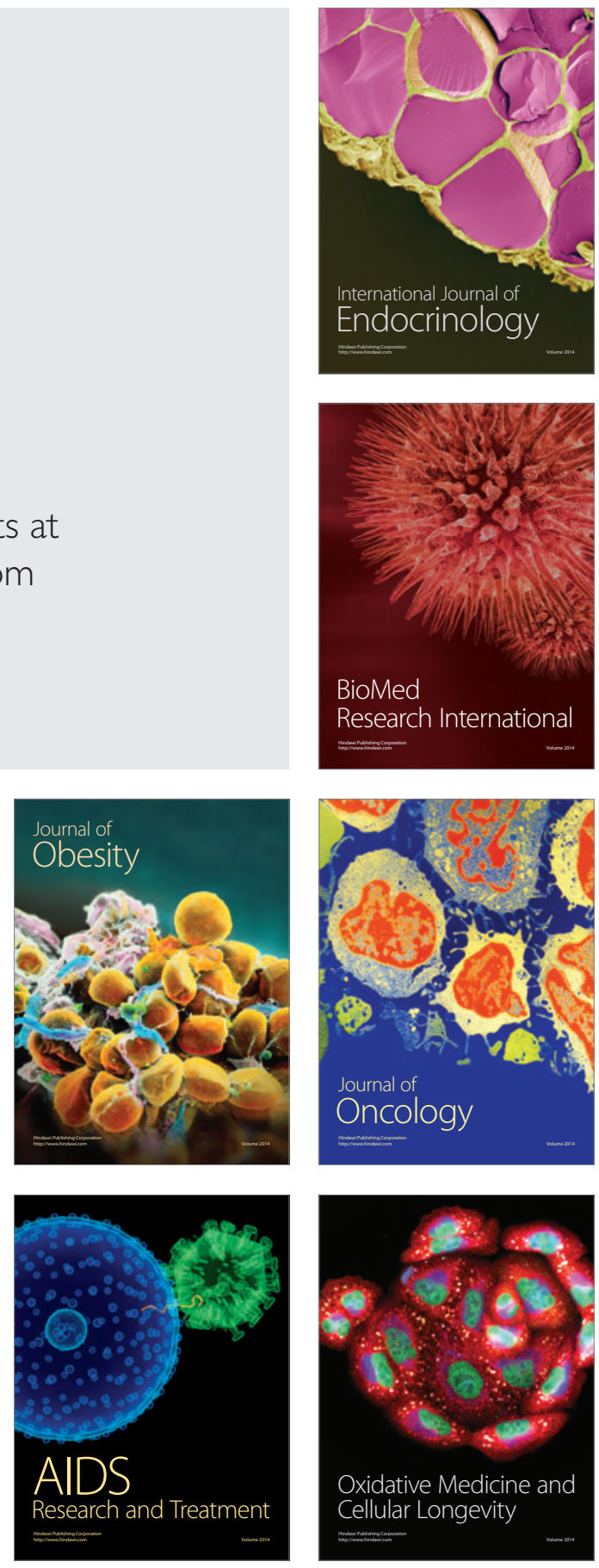